\title{
Integrative Action Process in the Perspective of Globalization
}

\author{
doi:10.3991/ijet.v3i1.738 \\ R. Pirinen \\ Laurea University of Applied Sciences, Espoo, Finland
}

\begin{abstract}
Transformations of knowledge and collaboration with international $R \& D$ experts are becoming increasingly common and an important part of international competitiveness. The object of Integrative Action is to integrate the three statutory tasks set for universities of applied sciences in Finland: education, research and development, and regional development. The constructive research question addressed in this article is: What are the constructions and models contributing to international and global activities, which are used in implementation and actualization by Finnish universities of applied sciences? The case in this article is Laurea University of Applied Sciences. The new proposition involves the Integrative Action model, with its elements and its applications from the perspective of globalization. The main contributions of the integrative action and process model are 1) the creation of a sustainable and linear framework for cyclic innovation activities and 2) the implementation of regional development and globalization perspectives Laurea University of Applied Sciences' everyday activities. The proposed models were applied and tested in higher education.
\end{abstract}

Keywords-education, globalization, integrative learning system, transformations

\section{INTRODUCTION}

It is evident that universities of applied sciences have evaluated the importance of regional and international development and collaborative work. Integrative action refers to the three statutory tasks given to universities of applied sciences being continuously integrated in everyday work and international cooperation, while emphasizing transformations and globalization. The term integrative refers to actions where students are at the center of authentic research and development work, and the university of applied sciences does not have its own, separate research and development organization; instead, it has a strong network involving other players in the innovation system, and its R\&D work is realized in a student-centered way.

Ref. [1] emphasizes that for learners this means: effective participation in authentic development and research projects; being at the center of development work; highly experimental learning; raised aspirations; social skills; self-confidence; personal responsibility for outcomes; contact with companies and organizations; coaching rather than instructional events; and a systematic way to attain relevant new last-known contexts.

Ref. [5] shows that the challenge involves changing the role of teachers, as well as increased guidance and coaching based on trust and equality, which is needed to produce professional growth. Evidently, learners are presented with a certain level of challenges during their learning cycle. With a good level of guidance, as well as an instructional scaffolding system [10] and coaching related to content and substance, we have the possibility to develop creative and innovative action within learning.

The role of integrative action in the innovation system of this sector is related to the existence of an expertise network, active and systematic participation in that network with students as equivalent participants in research. The link with globalization is that the university of applied sciences promotes the transformation of regional cooperation networks into innovators by transmitting and producing new knowledge, competence and innovations in the national and international innovation system.

Ref. [3] proposes that regional development and globalization have become the starting point for development and that the regional development task enriches learning. Predictive investigation of competences and technologies needed in their sectors by learners at the early stages of their studies puts positive, proactive pressure on the learning and on the content of academic studies. By proactive approach we mean causing something to happen rather than waiting to respond to an event. This proactive pressure is also an effective management and leadership skills development tool, as learners "learn to demand" the application of new knowledge and the learning of future core competences. The influence on the sector and on regional development comes from the nature of the work. In integrative action, practical $R \& D$ is defined from the perspective of the nature of the world of work, with valuable results achieved. Clearly, the nature of operations at a university of applied sciences is one of development.

\section{BACKGROUND}

The subject of this article is to create a new studentcentric model and practice that promotes effective globalization and integrative action through the implementation and actualization of the three statutory tasks given to Finnish universities of applied sciences (education, research and development, regional development).

\section{A. Description of Environment}

Finland is at the forefront of innovative culture and performance. Ref. [2] ranks Finland third out of the $27 \mathrm{EU}$ member states, and third out of 37 countries (including the EU countries, Croatia, Turkey, Iceland, Norway, Switzerland, Japan, the US, Australia, Canada and Israel), 
after Switzerland and Sweden respectively. The main reason for this is the high level of education and the strong cooperation and networking between the public and the academic and research sectors. Helsinki is the capital of a high-tech country, which has strong technological knowhow, especially in information and communication technology. The Helsinki metropolitan region, consisting of Helsinki, Espoo and Vantaa, has 1.24 million inhabitants and is developing into a "hub city". Hub cities are nodes in cross-border networks, which attract businesses, investors and tourists. Interaction with other countries is always essential for a small nation like Finland (with a population of 5.5 million). International business and research communities are expanding and Finland has to increase its efforts in internationalizing its innovations.

\section{B. Research Methods}

One obvious approach to this case is that of designscience and constructive research with action research [4]. The following concepts of constructive research were applied: (1) creation and execution of models; (2) evaluation of experimental implementation. The empirical case element, including design-science research and constructive development and analysis work, integrating the globalization perspective, was conducted between 2001 and 2008 in cases at Laurea's Espoo unit, in close cooperation with the Helsinki metropolitan area. The results are based on the identified best practices and empirical data collected at Laurea. Laurea conducts continuous action research on its own processes and has several online databases, whose content is used for action, research and development purposes.

\section{INTEGRATIVE ACTION MODEL}

Based on three tasks, integrative action builds bridges between technologies and applications so that research results can be turned into competence and economic success. Innovation alliances are to be made between various stakeholders, particularly in science, business and politics. In the integrative action model, vertical cooperation ("lead innovations") are geared toward certain services, applications and branches with specifically coordinated support contributions from technological areas. In the integrative cooperation, "technology alliances" pursuing technological objectives, created jointly with science and business, together with service platforms. This "lead innovation ecosystem" includes different type of cooperation, action and activities.

\section{A. Four Elements of Integrative Action}

There are several reasons for a clearer specification of the elements of integrative action. The first is the confusion in practical management. A completely different type of management is required for different actions; for example, if relevance-based action processes are managed in the same way as creativity and innovation actions, the result will be chaos; meanwhile, if creativity support is implemented as linear action, the outcome will be either very little innovation or no innovation at all. The second reason is the core idea behind "changing of objectivity", which refers to the balancing of subjectivity and objectivity to support creativity. It explains how and in which parts of the process objectivity and subjectivity are used to support creativity. The third reason is that commercially beneficial innovation is impossible without radical interventions, so cyclic orientation is different from others. The fourth reason is the fact that we live in a time of globalization. While the population's average age rises, the actual population is decreasing in size, which means that future business will focus more on creativity and innovation. The fifth reason is that good quality is important and also it differs between different actions, so the nature of the elements must be analyzed to lead to a quality system that takes creativity and innovation better into account. Based on these reasons, a clearer definition is sorely needed in order to differentiate between and clarify different actions. In this case the four elements specified for integrative action are: 1) cyclic; 2) thematic; 3) linear; and 4) relevance.

1) The cyclic element emphasizes regional and global support for creativity and innovation. It allows for meaningful "valuable subjectivity-objectivity changes". It integrates different inspirational actors, creative sources and innovation systems, which together make up a "lead innovation ecosystem" [28], i.e. a cooperational center of lead innovations and technology alliances. A triple helix [12] structure is usually linked to innovations, which are: (1) the dynamics of interactions and communications among academia, industry and government produce on themselves and (2) on the social mechanisms of selection, variation and retention responsible for their evolution as sectors.

2) The thematic element represents a co-creative collector: it produces a full duplex transformation practice for collecting promising activities and things with action of development realities; it is an interface for a community of networked experts focused on cyclic activities; it integrates Living Labs [11] that emphasize bringing science and innovation closer to citizens and inspiring interest in them; it makes realizations that represent linear activities; and it regulates wishes from "innovation dreams nature" to the real realization possibilities. In practice, this means a communal perspective and answers what, why and how innovative ideas, artifacts and things are possible to implement.

3) The linear element produces specifications and defines the boundaries of objects $[15,16]$. It executes the development and implementation part in the integrative action process. It is linked to developing and using a large number of methods and standards, including standards of development, quality, service, design, continuity, security and maintenance.

4) The relevance element means quality and feedback. It answers the questions such as: Is our action relevant? Have the necessary quality standards been implemented? What other relevant perspectives should be taken into account? It also creates new starting or action points to process, and includes evaluation perspectives, as well as impact and action research perspectives. It represents the potential standardization aspect of global integrative action. The EFQM Excellence model provides the holistic framework around which an organization can assess the use of these tools and standards, and choose the tools required to move forward. The British Quality Foundation and standards such as ISO 9001:2000 provide complementary rather than competing approaches for the case of integrative action $[17,18,19]$. 


\section{B. Orchestration Model}

Interaction between orientations, including different transformations, is an important factor for supporting creativity in the innovation system. The orchestration [27] model proposes that the existence of innovation orientation and creativity depends on the nature of objectivity, the type of transformations, the existence of orientation and support for creativity. A transformation exists between different orientations, and different instances of orientations exist simultaneously in the process of creative integrative action. The orchestration model is an abstract; it illustrates and provides the models for the operation of a creativity support system. As regards innovation, if the necessary creativity and inspiration for innovation exist, the results are evaluated but not formalized and valued in advance. This implies using variations of objectivity and scopes to support entity for creativity. The model suggests that the nature of objectivity changes during the transformation of the orientations, and that the nature of objectivity depends on the orientation itself. The phenomenon of changing objectivity is mainly innovation-based, and it exists in the transformation from some orientations to the innovation orientation. The orchestration model emphasizes the role of proactivity, which refers to causing something to happen rather than waiting to respond to an event. In the innovation orientation, a criterion and "be based on things and types" are born on cycles of creativity and inspirational transactions. The model points to a balanced relationship between orientation and transformation, as well as the different roles of scopes and objects in the innovation system. The orchestration model is illustrated in Fig. 1.

In the linear reactive model-based orientation, only few innovations and new competences exist, and evaluation indicates them as to "be based on objectivity". In the linear problem-based orientation, the basic idea and development objects are usually well known and defined. The traditional research questions and objectives on which objectivity is "based and justified" are usually formulated and fixed. Objectivity typically means that linear, formal, defined and reactive interventions, including criteria and evaluations, stick to objectivity. This is manifested in educational practices in that subjects (namely teachers, evaluators, experts and students) try to maintain a good level of objectivity, and typically "be based on objectivity". This works in exams and in the instructional system, but a side effect is that learning and cyclical creativity are separated by strong boundaries, which means that learning interventions are limited to a linear and controlled area. In the cyclic innovation orientation, there are no ready-made, justified criteria based on objectivity. Different methods clearly help and contribute to the area of linear orientation, but there is no formal solution for random and cyclic innovation processes. Therefore, the orchestration model is seen as a support structure for creativity.

The orchestration model involves a synthetic transformation process, where the term synthetic is not the same as a "compromise", but the integration of different and opposing aspects through a dynamic learning process [14]. Synthetic transformation is achieved through a trinity (valuable objectivity, value creation and action in a value network), and action is based on a shared context which has meaningful links with motivation. The motivation perspective is emphasized because it generates the needed attraction and intensity for knowledge acquisition and constructivism [10]. The starting point of the synthetic transformation process may be an object, a scope, a theme or an interesting part of the innovation

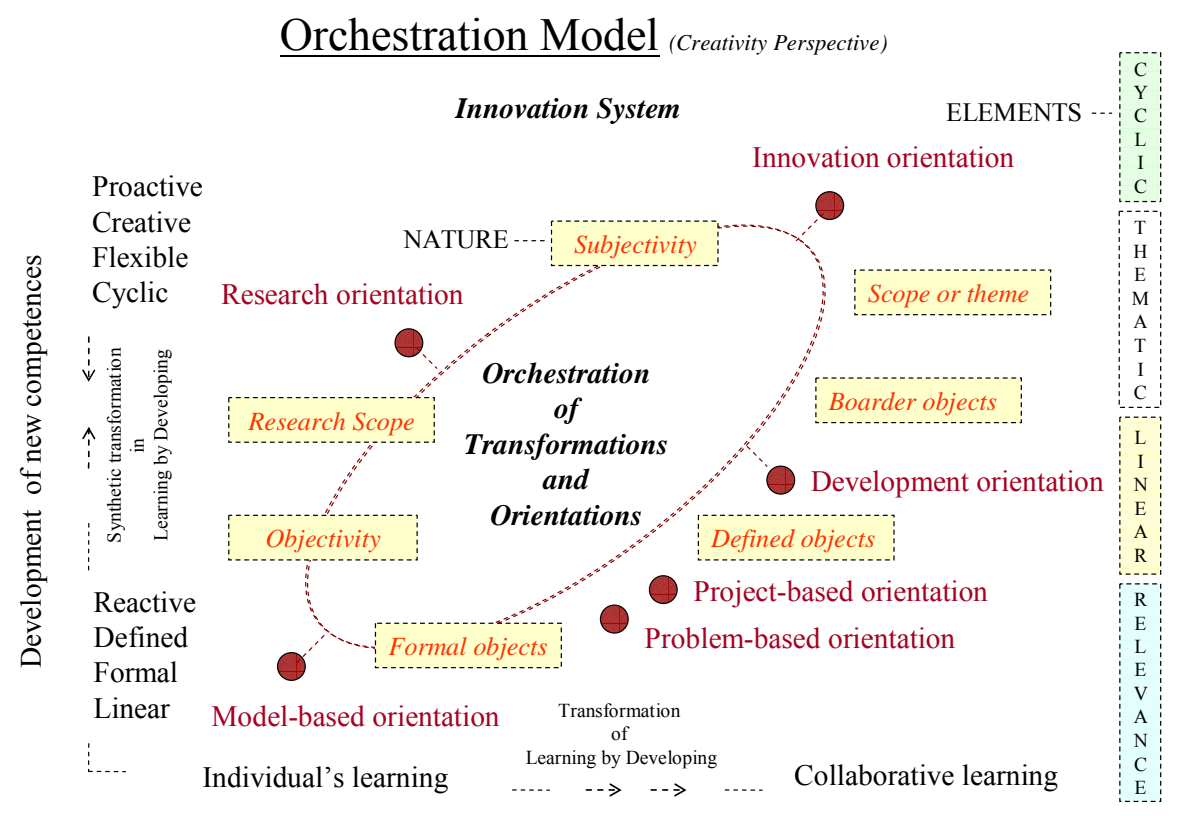

Figure 1. The orchestration model proposes that objectivity and the type of scopes change during transformation to the innovation orientation. The orchestration model supports the construction of creativity and an innovation system. Orchestration of transformations and the interactions between orientations is performed in the integrative action process. The elements are used for the interfaces of different systems. 
system. The "why" and "what" have to be clear enough at the start of transformation. The mentioned scope, domain, theme and interesting area refer to "a regions of imagination inside" in which properties and things are uniform. This refers to communities that have equal or complementary interests and that add creative actions to as yet non-existent objects or creations. A synthetic transformation process may continue through shared flexible things, using the "freedom within framework" principle, where inside participants own development and decisions on "how", future value and opportunities.

The orchestration model describes the need for different orientations. All orientations are important and necessary; the model emphasizes the relation of the vitality and creativity of orientation and the nature of objectivity. The orchestration model also plays a crucial role in organizational management and leadership culture. The implementation of the model creates possibilities for the applied vision-based and "supporting innovation-based" leadership model. The main contribution of the orchestration model is that the different orientations together compose an orchestrated ecosystem where creativity is supported and valued.

\section{Integrative Action Process}

The integrative action process is an application used in the best practices of exploratory and creative learning [3]. The objective was to implement and integrate the three statutory tasks in the context of services, service design, security and ICT in the case of Laurea University of Applied Sciences. The integrative action process is illustrated in Fig. 2.

The main contribution of the integrative action and process model was the creation of a linear development framework for cyclic innovation activities with a quality perspective. The model itself is a liberation process [3] for innovative activities, rather than a process for automatic innovation generation. The innovative learning cycles do not follow any fixed order [7] and the freedom of methods and creativity are emphasized in the innovation orientation [13]. Hence, the nature of the integrative process is supportive rather than managerial in the cyclic and thematic elements, and objective in the linear and relevance elements. In this case, the objective was to develop, help and support the construction of innovations and creativity. This process combines changing orientations and synthetic transformations in a systematic way.

The framework described in the trimming process model has five components: science and innovation (cyclic) (1); collector of co-creative objects, emphasizing full duplex transformation functions (thematic) (2); development (linear) (3); results (relevance) (4); and quality (relevance) (5). The starting point of the implementation process may be any of the components from (1) to (5). The starting point varies and depends on the objectives and perspectives.

The science and innovation component (1) emphasizes creativity and includes the elements that solidly link research on future information technology (lead innovations) and new service generation together. The research ranges from the implementation of fundamental methods and new technologies to the creation of novel applications and services, and their action impact on people, the region and society. In this case it also involves service design, innovations and responsibility.

The objectives of service design are planning and organizing people, infrastructure, communication and the material components of a service, in order to improve its quality, the interaction between the service provider and the customers, and the customers' experience.

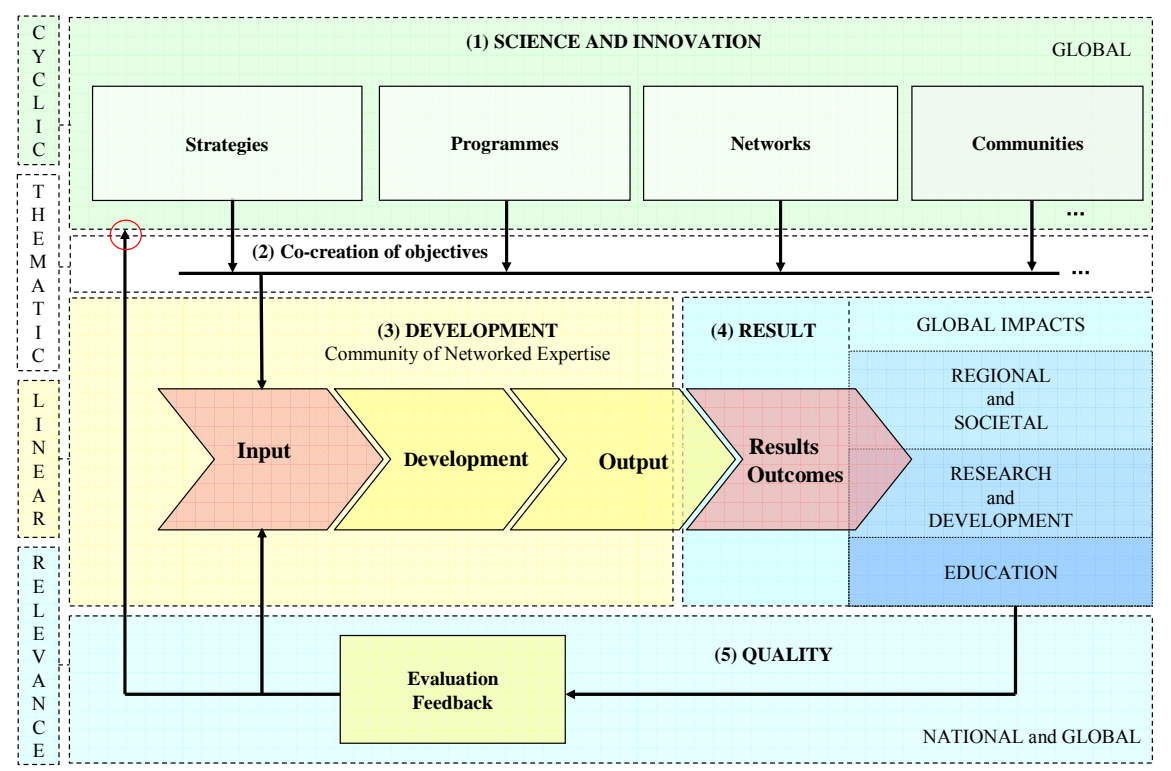

Figure 2. The Integrative action model is an application used in the best practices of exploratory learning. The objective was to implement and integrate the three statutory tasks in the context of services, service design, security and ICT in the case of Laurea University of Applied Sciences. The main contribution of the integrative action and process model was the creation of a linear development framework for cyclic innovation activities with a quality perspective. The elements were used as full duplex and co-creative interfaces. 
A cyclic activity for development objectivities and objects strategies and future programmes e.g. the programmes of the ICT cluster of the Finnish Strategic Centres for Science, Technology and Innovation ICT SHOK and constructions of lead innovation systems.

The innovation component emphasizes cooperation in a community of practices built around shared expertise or a new project that the members of the community agree on and for whose future development they take joint responsibility.

The collector of objects component (2) represents the function of linearization of creative objectives to be more like "boundary objects with flexibility $[15,16]$ " for development. There are many suitable and useful development and research methods for cyclic to linear transformation and process realization. The first useful example is the progressive inquiry (PI) model [6]. The PI model describes the elements of expert-like knowledge practices in form of a cyclic inquiry process, producing synthesis and defined results.

The linear development component (3) refers to development methods and cooperation in communities of networked expertise. From the learning perspective, it means expertise that arises from social interaction, knowledge, competence sharing, research and problemsolving related to collective and specific objects. The development component emphasizes cooperation and creating a "learning and developing" culture. It makes it possible to include and use various scientific perspectives and methods of learning by developing and researching in operation and action. Suitable development methods are available for process realization. One example of implemented cases is the rational unified process (RUP). The RUP model's aim is to contribute to the building of resilient systems that can grow and adapt to new needs [20].

The process results component (4) is presented from the perspectives of the three tasks of universities of applied sciences, namely (1) education; (2) research and development; and (3) regional and societal development. The results also have increasing effects on globalization, and that is why global impacts 4) are included in the results of the process. the regional development task creates possibilities for value and knowledge transfer to innovations, new services and improvement of productivity, new business and Living Lab environments linked to global markets, vitality of networks, safety improvements, welfare and increased global impact. Regional, societal and global impacts are drivers for the creation of new knowledge. The value and prospects associated with competitiveness underscore the importance of knowledge transfer and its ability to enhance innovations and new services. The impacts of the action model include full duplex transfer between the local and global levels.

The relevance component, (5), includes quality management at the national and global level. Laurea's Quality Management System (QMS) and quality activities are implemented currently on a local level. The QMS is based on Laurea's values and strategic intent, and on the strategies derived from these. The aim of the system is to systematically produce quality-related data, make functions visible and produce materials for developing operations and processes. The quality management system provides a general view of the links between the different elements of quality development, and identifies the responsibilities of various parties. The system is used to harmonize and increase the efficiency of operations. It provides the context for systematizing functions, while allowing for unit-specific solutions. Laurea's quality documentation describes the management system as a whole, defining the objectives of quality efforts, the organization and the responsibilities of quality and evaluation work. The key quality process of Laurea is development process, and in this case it refers to the quality of the integrative action process [26].

The integrative process manages the innovation and execution process, which makes it possible to use feedback operations. The results are of course useful past the implementation of new or further studies. The project carried out in the learning environments allows for constructive development of context and learning. The cyclic and creative objectives of the inception and elaboration phases are then continued with the linear implementation process. This typically involves the implementing learning and developing methods, integrating culture-dependent factors and managing the environment.

In the integration model, the themes, topics or scopes do not need to be formally very sophisticated; the idea is that the creative object $[8,9]$, case or scope is interesting and really motivating for the participants. The integration of the framework is designed to facilitate engagement through the building of motivation and trust for participants; in this case, students are equal participants. The participants' competences and own key values and identities must support the object's interest. This means that the participants should have a high motivation for development work. The implementation of integrative action is illustrated in Fig. 3.

The starting point of the development project is often the shared co-creation of ideas, and the findings from contexts are linked to the innovation and creativity object, scope or theme. Trust is crucial in order to build relationships among network participants. If any participants did not have adequate personal motivation objects for innovating, then the Strategic Centre of Science (SHOK), the European Network of Living Labs (ENoLL) or another lead innovation source briefly discussed objects for such new, active developers. Allowing creativity and flexibility of objects is especially necessary in the "innovation circle", which is an inspirational and cyclic process where spirit and flow play a crucial role. It is illustrated on the right side of Fig. 3. It was necessary for participants to agree that the modified object or case was sufficiently innovative, motivating and worth a personal commitment to development.

At the level of co-creation, the idea, issue, agenda, object and creativity amplify the innovation process. Issues and agendas include object candidates, but an important aspect of the innovation process is that students are equal participants and generate their own creations [10]. In other words, instances of the object or topic guide the students' creativity and innovation, not the teacher's innovation. This is because creativity is the target. Without the participants actively generating ideas, there can be no adequate motivation in the process. [6] The co-creation is mainly a "flexible interface" and "knowledge transfer enabler", rather than a ready-supported construction of the 

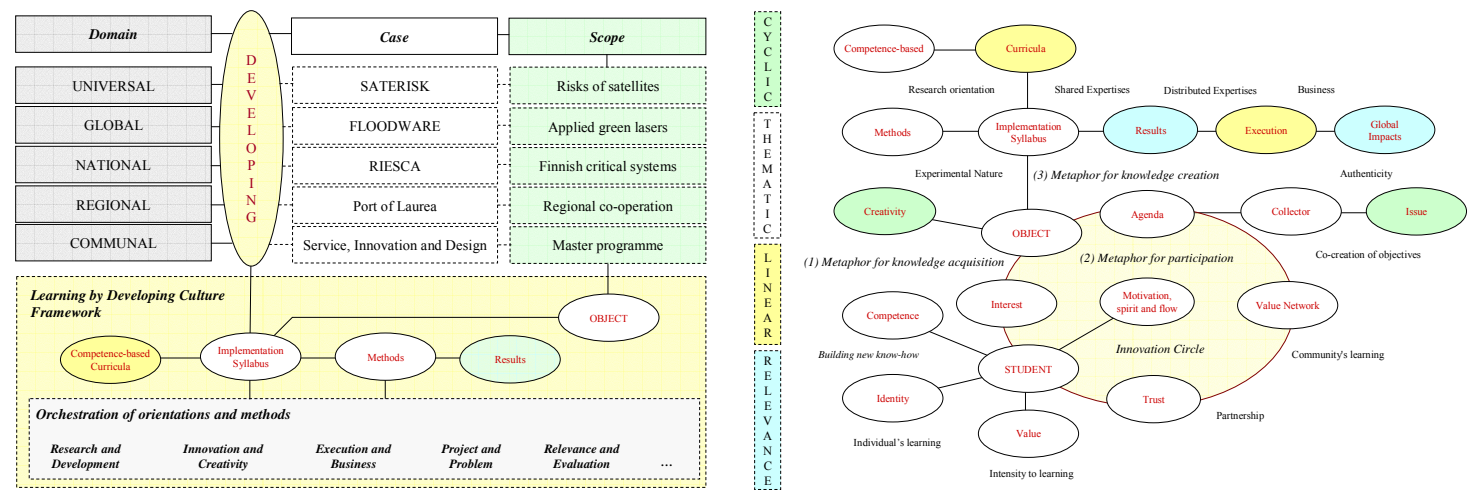

Figure 3. The implementation of the integrative action model binds the elements with the cases, scopes and implementations of study courses. The implementation case model represents terms of action in form of nouns and linking verbs, and places the dimensions of LbD [13] and the three learning metaphors [10] in the same framework. Reading example: a student has an interest relation with an object and identifies the value of the object. This creates more competence, identity and value for the student and also increases motivation and intensity of learning related bases. It extends the student's trust, social participation and partnership within the value network. The elements are connected to the nouns with like colours.

commissioned project. The creative starting points are often evolutionary artifacts by the cooperating participants of the value network (lead innovations) integrated together by the professional developers from research and development organizations. At the societal level, the strategic research objects are also released and carried out in a strategic research agenda (SRA).

In this flexible and enabling way, the integrative action process makes and binds the path for creativity, innovation and the development process, starting from an individual's "key drivers" (interest, competence, motivation, identity, value and trust) and ending in globalization possibilities.

\section{CASE STUdIES}

The cases implemented at the Bachelor level of higher education took place in Hospitality Management, Security and ICT, and involved 1,120 students. Those at Master's level were in Service Management and ICT, involving 56 students. Currently, there are more than 30 active and collaborative projects using the integrative action model. The selected cases presented below illustrate different types and the spread of the implemented types of cases.

Service, Innovation and Design (SID). The strategic objects are collaborative development of service innovations and new competences in service design. Laurea is an associate member of the International Service Design Network, which activates the development of new services for the public sector and business, arranges various business events, researches and develops innovation networks, and researches the challenges faced by various actors in the course of developing new services [21]. This case was implemented in Hospitality Management and ICT.

Laurea Living Labs (LLL) is a member of the European Network of Living Labs (ENoLL). ENoLL has a Europewide platform for providing user-driven innovation capabilities and services to small and medium-sized enterprises, international corporations, public sector agencies, academic institutions and individual citizens. LLL is an approach to stimulating and accelerating industrial and societal innovation. It is also a way of connecting and empowering users to participate in research, development and innovation [22]. This case was implemented in Hospitality Management and ICT.

The case of Rescuing of Intelligence and Electronic Security Core Applications (RIESCA) is targeted to contributing methods of systems that are critical in the national perspective. The research object is to produce information security and continuity management methods that can be used to ensure the proper functioning of critical systems under varying circumstances. Furthermore, it leads to the development of integrative action and an environment for critical system development, management and evaluation. The case uses the integrative action model and its participants include more than ten international companies and three Finnish higher education institutions The scopes and themes of RIESCA are implemented in several Security and ICT courses. The full duplex knowledge transformation is used with one of the largest independent research centers in Austria in the field of software, Software Competence Center Hagenberg (SCCH).

The examples of new security and ICT cases are SATERISK (risks of satellites) and FLOODWARE (flood readiness and research of flood systems), both global, large $R \& D$ projects. The integrative action model was implemented for enabling knowledge creation and globalization of transformations. The idea, application of foundation, focus, themes, topics and spirit of SATERISK were done by students, so SATERISK is purely a student innovation and creation

The regional, institutional development and globalization case example is LaureaLabs. It is an international expertise cooperation network involving international developers and researchers, which facilitate knowledge transfer and ultimately enables regional development. The network actively involves international trainees who contribute to regional development by generating services and research data in different fields of expertise. It also includes applied $R \& D$ projects that contribute innovative and creative solutions to specific problems and needs in companies and industries operating in rapidly changing, knowledge-intensive fields. 
The next globalization examples are Port of Laurea and Laurea Village, both of which are used in an international learning concept developed to attract talented Finnish and international students and researchers. The focus is on optimizing existing services and implementing new, necessary services for availability, facilitation and support. Laurea Village aims to combine education, research and development. Communities of networked expertise are cultured from students, researchers and representatives from working life. These communities work in real-life projects to produce knowledge for the academic, public and private sectors in the Helsinki metropolitan area.

\section{RESUlTS AND DisCUSSION}

The main contribution of the integrative action and process model is the creation of a linear development framework for cyclic innovation activities with a quality perspective. The model itself is rather a liberating process for innovative activities than the process of an automatic innovation generation machine. The implemented elements - cyclic, thematic, linear and relevance - clarify the styles of management, the role of objectivity, the special needs of radical innovations, the role of society in the world of globalization, and the contribution and evaluation of creativity and innovations, measured in a local educational quality system.

The implementation of the integrative action model and the third task in the integrative way are challenging in the everyday operations of the university of applied sciences, because the paradigm shift in education from traditional methods to methods based on knowledge-creation through research, development and learning. Building a business that can outlive good ideas, products and services depends on a culture [5] that values learning and supports creativity and radical innovations. If we want to support the career possibilities of students that allow them to grow into responsibilities and trust in the knowledge expertise community, then we have to make sure teachers, participants and managers are learning continuously with them. If managements are not participants in the integrative action process, action is not effective.

It is important to learn strong theoretical bases for the large understanding and reaching sustainable base of knowledge and competences for proactive needs. The important parts of the ICT base are growing faster than anyone can even read or think about them. This integrative action concept motivates theoretical studies using a scaffolding structure [24], and emphasizes the fact that the best learning depends on human nature. It ensures that the motivation link exists and that the three learning perspectives are clustered with each other.

Ref. [25] proposes that if innovation-center based objectives (lead innovations) are used in higher education, learning actions create deeper and more relevant knowledge and competence for the communities of expertise than the themes or areas of interest of the workplace or the student would. This is reasonable, because the innovation topics and research areas of innovation centers are deeply verified and analyzed, even from a futurology perspective. This does not include big contraction with creativity, as it is still possible to keep the creative scopes and themes of innovation center flexible, motivated and creative enough for students in integrative action process.
Ref. [1] identified the challenges as the system, which relies heavily on group commitment, motivation and coaching, the problem of how to reach creative objects and up-to-date knowledge (last known context) more systematically, the fact that self-learning takes much longer than coaching (and whether this is inevitable in learning related to real development) and the difficulty of establishing the optimum ratio of direct inputs and creative objectives and initiatives.

Higher education institutions can promote knowledge transfer through their international operations. This makes the greater Helsinki metropolitan area a genuinely international and multicultural innovation environment that has strong functional links to other top innovation regions in the world, and strategic alliances with top universities in the world. The region endeavors to form an international community by setting up internationally attractive and innovative R\&D projects and institutionalizing effective operating models for innovation. Learners at all levels of higher education are usually seeking ways to improve their research and acquire new competences, so an international value network gives them new concrete prospects and possibilities to continue their studies in a global perspective.

National evaluations have recognized the innovative learning and future-oriented development of the integrative model. For instance, integrative action and internationalization efforts influenced Laurea's appointment as a centre of excellence in regional development for 2003-2004 and 2006-2007, and as a centre of excellence in education for 2005-2006 and 20082009. [23] The Finnish Higher Education Evaluation Council (FINHEEC) is an independent expert body assisting universities, universities of applied sciences and the Ministry of Education in matters relating to evaluation, and thus contributes to improving the quality of higher education. The twelve-member Evaluation Council operates under the auspices of the Ministry of Education.

An improvement of the relevance element is needed in future. It represents a possible and meaningful standardization element of global integrative action, which opens possibilities for defining collaboration platforms for global higher education and integrative action on the relevance level. Standardization of thematic or cyclic elements should boarder creativity and limit institutions' strategic competition, but cooperation should be increased at the cooperational service level and services may create expertise and Living Lab networks e.g. using web service technologies. The EFQM Excellence model provides the holistic framework around which an organization can assess its use of these tools and standards and choose those necessary to move it forward. The British Quality Foundation and standards such as ISO 9001:2000 provide complementary rather than competing approaches for the case of integrative action $[17,18,19]$.

Although formal research - especially research results and relevant problems - is a good starting point for the innovation process, more creativity-supporting, global thinking and transformation from reactive to proactive direction is needed. Innovations can be born without research or even relevant problems, but they always involve inspiration and perspiration - inspiration meaning creativity and perspiration meaning development work, 
which are always needed and must be present before an innovation can be introduced to the global markets.

There are three terms present in the innovation orientation, namely: support of creativity; multidimensional transformation; and space with spirit and flow. Creative learning is related to human nature, which is understood. Different kinds of methods clearly help and contribute to the area of linear orientation, but there is no formal solution for random and cyclic innovation processes. Therefore, freedom of methods, applications, changing of objectivity, spirit, flow, transformations and trust exist in the world of cyclic innovation orientation, which also includes creative learning.

\section{ACKNOWLEDGEMENT}

I want to thank all my students for their work and contributions in using integrative action, as equal researchers and developers.

\section{REFERENCES}

[1] Vyakarnam, S., Illes, K., Kolmos, A. \& Madritsch, T. Making a Difference. A Report on Learning by Developing - Innovation in Higher Education at Laurea University of Applied Sciences, Laurea Publications, Edita, Helsinki, 2008.

[2] "European Innovation Scoreboard 2007 (EIS 2007) Analysis of innovation performance". Report by the Maastricht Economic and Social Research and Training Centre on Innovation and Technology (UNU-MERIT) with the support of the Joint Research Centre (Institute for the Protection and Security of the Citizen) of the European Commission. (http://www.nordforsk.org/ img/euro pean innovation_scoreboard 2007.pdf).

[3] Fränti, M. \& Pirinen, R. Tutkiva oppiminen integratiivisissa oppimisympäristössä. Laurea Publications, Edita, 2005 (in Finnish).

[4] Järvinen, P. On Research Methods. Tampere: Juvenes-Print, 2004.

[5] Pirinen, R. \& Fränti, M. "Learning by Developing". Information Technologies: Theory, Practice, Innovations, International Conference, Alytus College, 6-7 December 2007.

[6] Hakkarainen, K., Lonka, K. \& Lipponen, L. Tutkiva oppiminen. Älykkään toiminnan rajat ja niiden ylittäminen. Porvoo: WSOY, 1999 (in Finnish)

[7] Engeström, Y. "Expansive learning at work. Toward an activitytheoretical reconceptualization", Journal of Education and Work, vol. 14, no. 1, pp. 133-156, 2001. (doi:10.1080/13639080123238)

[8] Bereiter, C. Education and Mind in the Knowledge Age. Mahwah, NJ: Lawrence Erlbaum Associates, 2002.

[9] Bereiter, C. \& Scardamalia, M. "Learning to work creatively with knowledge", Powerful Learning Environments. Unravelling Basis Components and Dimensions (pp. 55-68). Oxford: Elsevier, 2003.

[10] Hakkarainen, K., Palonen, T., Paavola, S., Lehtinen, E. Communities of Networked Expertise: Professional and educational perspectives. Amsterdam: Elsevier, 2004.

[11] Pirinen, R. "Integrative Learning Environments in Perspective of Regional Development. Learning Regions' Role in Regional Development and Re-Generation", Pascal International Conference, University of Limerick , 28-30 May 2008.

[12] Etzkowitz, H. \& Loet, L. "The Endless Transition: A Triple Helix of University-Industry-Government Relations", Minerva 36: 203208, 1998. (doi:10.1023/A:1004348123030)

[13] Pirinen, R., Fänti M. "Integrative Learning Environments in Perspective of Globalization Models and Effects in Higher Education". International Conference (ICL2008), 24-26 September 2008, Villach, Austria.
[14] Ichijo, K., Nonaka, I. Knowledge Creation and Management: New Challenges for Managers. New York: Oxford University, 2006.

[15] Star, S., Greisemer, J. "Institutional ecology, 'translations' and boundary object. Amateurs and professionals in Berkeley's Museum of Vertebrate Zoology", Social Studies of Science, 19, 387-420, 1989. (doi:10.1177/030631289019003001)

[16] Star, S. (1989). "The structure of ill-structured solutions: Boundary objects and heterogeneous distributed problem solving". In L. Gasser \& M. N. Huhns (Eds.), Distributed Intelligence (pp. 37-54), London: Pitman, 1989.

[17] The British Quality Foundation (BQF) is an independent, not-forprofit organization founded in 1993 by the DTI and leading businesses. (http://www.quality-foundation.co.uk/links.htm).

[18] EFQM Excellence Model (1999) (Brussels, EFQM). The EFQM Excellence Model was introduced at the beginning of 1992 as the framework for assessing organisations for the European Quality Award. It is now the most widely used organizational framework in Europe and it has become the basis for the majority of national and regional Quality Awards. (http://www.efqm.org/ Default.aspx?tabid=1).

[19] ISO/DIS 9000:2000 (1999) International Organization for Standardization. Management system standards provide a model to follow in setting up and operating a management system. This model incorporates the features on which experts in the field have reached a consensus as being the international state of the art. (http://www.iso.org/iso/home.htm).

[20] Jacobson, I., Booch, G. \& Rumbaugh, J. The Unified Software Development Process, Addison-Wesley Professional, 1999.

[21] The International Service Design Network activates the development of new services for public sectors and companies, arranges various business events, researches and develops innovation networks as well as researching challenges faced by various actors in the course of developing new services. (www.service-design-network.org).

[22] Laurea Living Labs (LLL) is a member of the European Network of Living Labs (ENoLL). Living Lab is a new concept for R\&D and innovation to boost the Lisbon strategy for jobs and growth in Europe. (http://www.cdt.ltu.se/ zcorelabs).

[23] Salminen, H. \& Kajaste M. Laatua, innovatiivisuutta ja proaktiivisuutta Ammattikorkeakoulujen koulutuksen laatuyksiköt 2005-2006. Finnish Higher Education Evaluation Council. Tampere: Tammer-Paino Oy, 2005 (in Finnish).

[24] Rajamäki, J., Pirinen, R. "Linkage of Learning by Developing and Virtual Learning. Case: Network Design Specialisation Studies". In: European Computing Conference (ECC 08), WSEAS, 11-13 September, Malta (2008), pp. 397-402.

[25] Kotila, H,, Auvinen, P. Tie vastuulliseen johtajuuteen palveluliiketoiminnan arviointeja. HAAGA-HELIA Publications. Helsinki 2008 (in Finnish).

[26] Laurean Laatukäsikirja (2008). Laurea Publications. (in Finnish) (http://www.laurea.fi/internet/fi/03 tietoa_laureasta/01/07_Laatu/1 aatukasikirja2008.pdf).

[27] Erl, T. Service-Oriented Architecture. Concepts, Technology, and Design. Boston: Prentice Hall, PTR 2005.

[28] Digital Business Ecosystems, European Commission, Information Society and Media, 2007. (http://www.digital-ecosystems.org/dbebook-2007)

\section{AUTHORS}

R. Pirinen (e-mail: rauno.pirinen@ laurea.fi) is with the Laurea University of Applied Sciences, Espoo, Finland.

This article was modified from a presentation at the International Conference of Interactive Computer Aided Learning ICL2008, September $24-26,2008$ in Villach, Austria. Manuscript received 28 November 2008. Published as submitted by the author. 